\title{
Augmenting Cleansing Process for Reducing Occupational Hazards Experienced by Labours Handling Pyrotechnical Chemicals in Firecracker Units
}

\author{
Vishnuvarthanan Govindaraj, Pallikonda Rajasekaran Murugan, Sakthivel Sankaran, Sathiyaa \\ Sri Suthanthiram, Jothi Malar Thirumurugan, Mohamed Sheik Mydeen Ismail, Arjunan \\ Senthilkumar
}

\begin{abstract}
The value of Human resource is considered to be very important in fire work industries. Nearly $90 \%$ of fire crackers are manufactured in Sivakasi, which is considered to be the hub of fireworks production in India. The manufacturing process, type of storage and handling of chemicals are some of the important factor which bears the responsibility of affecting the worker's health. Firecrackers manufacturing involves mixing of various chemicals. Moreover, it leads to lot of health issue to the workers like respiratory disorders, skin problems, damage to kidney, mental impairment and eye irritation, also it can cause cancer. Out of these major problems, skin and respiratory issues are mainly caused due to the direct handling of chemicals without safety precautions. Chemicals such as Sulphur-di-oxide, copper nitrate and magnesium are highly used in manufacturing the crackers. In order to overcome these hazardous problems, we have planned to make a soap for the affected people through precipitation method, using organic solvent (ETHANOL) and with the mixture of alum and sodium lauryl sulphate salts. The main aim of doing this project is to give a product of low cost with longevity and with good quality, which provides ample protection through cleanliness to the people who work in fire cracker units.
\end{abstract}

Index Terms: Firework industries; Safety requirements; Health hazard reduction; Allergic prevention.

\section{INTRODUCTION}

Sivakasi is a town in Virudhunagar District in the state of Tamil Nadu in India. This town is known for its

Revised Manuscript Received on December 16, 2019.

Vishnuvarthanan Govindaraj, Department of Biomedical Engineering, Kalasalingam Academy of Research and Education, Virudhunagar,Tamilnadu, India. (email: gvvarthanan@gmail.com)

Pallikonda Rajasekaran Murugan, Department of Electronics and communication Engineering, Kalasalingam Academy of Research and Education, Virudhunagar,Tamilnadu, India. (email: mpraja80@gmail.com)

Sakthivel Sankaran, Department of Biomedical Engineering, Kalasalingam Academy of Research and Education, Virudhunagar, Tamilnadu, India. (email: sakthivelsankaran1992@gmail.com)

Sathiyaa Sri Suthanthiram, Department of Biomedical Engineering, Kalasalingam Academy of Research and Education, Virudhunagar, Tamilnadu, India.

Jothi Malar Thirumurugan, Department of Biomedical Engineering, Kalasalingam Academy of Research and Education, Virudhunagar, Tamilnadu, India.

Mohamed Sheik Mydeen Ismail, Department of Biomedical Engineering, Kalasalingam Academy of Research and Education, Virudhunagar, Tamilnadu, India

Arjunan Senthilkumar, Department of Biomedical Engineering, Kalasalingam Academy of Research and Education, Virudhunagar, Tamilnadu, India. manufacturing of firecracker, matchbox and printing industries. Large amount of firecrackers are manufactured in Sivakasi and so, it was named as "LITTLE JAPAN" and "FIRE HUB OF INDIA".

A bright light and sound given for us on festivals is coming from the dark side of the fire workers in Sivakasi. Fireworks industry is well known to be a hazardous industry. Right from the initial phase of manufacturing till the transportation and storage of fireworks in the stores, risk to life and property is high.

The manufacturing process, type of storage and handling are some of the important factors which bear the likeliness of an explosive event taking place. In Sivakasi, there are around 450 firework factories with direct employment about 40,000 workers and indirect employment of 1,00,000 workers in the country side. The manufacturing process or an assembly of crackers is in critical phase, where workers come in direct contact with hazardous substances leading to greater life risk. Lead poisoning, ulcers, damage to the central nervous system are some of the major problems faced by these people. Besides unhygienic conditions, improper training pose a great threat to the lives of people.

\section{A. Review Stage}

To reduce the hazards, we try to remove the microorganisms and chemicals from the worker's skin by altering the chemical substances from the soap, that are currently in use which is having the high amount of sodium hydroxide that leads them to various skin disorders. The workers didn't have any awareness about their cleansing method, especially soaps. So, we plan to make a soap product by using "ALUM" salt, which is having an antibacterial property against the pathogenic microorganisms. Therefore, we can remove the chemicals and treat the affected skin areas.

\section{LITERATURE SURVEY}

On analyzing many literatures related to the subject matter of this paper, most of the works done or perceived are related to fire accidents occurring in the fire industries, then safety measurements given by the Fire and Safety Association of India (FSAI), then many mathematical papers to get the census list of factory and the problems of workers and also

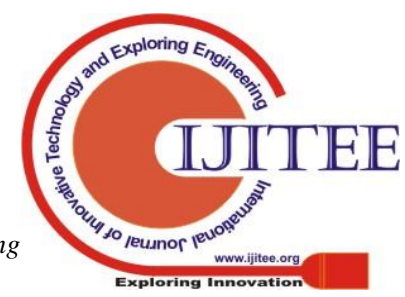


a math derivative for comparison of companies and comparison between the two company workers.

Some of the papers only reveal partial problem of the workers (health issues) and the risk of works in firework industries, which is a main drawback for the workers. If someone tries to solve it, they don't have enough details about how to pursue it. We hope that our paper will overcome the health issues of the employees of firecracker units. This has been achieved by altering the traditional cleansing method through the usage of an antibacterial soap that can remove the chemicals and pathogenic bacteria present in the skin.

[1] This paper discloses the information regarding the chemicals which are used for the manufacturing of crackers and their side effects caused due to the direct handling of chemicals, and this is the main advantage of this paper and the authors have done the analytical test for workers using their hair, which is represented in graphical representation. But like the other papers, they did not mention the diseases caused to the workers.

[2] didn't get the problems of the workers through papers but listed their basic needs through this paper about, "THEIR SAFETY MEASUREMENTS" which will lead us to design a better product for the prevention of fire-accidents in the workplace. This paper describes the national safety measure rules for the workers. In this, they have included the timing and procedure for manufacturing, then the safety equipment's which must be provided for them from the factories. This analysis may reveal the rules and create awareness to the workers. There are few industries which follows the rules. Unfortunately, workers refuse to use it, because of they feel uncomfortable during their works.

[3] The aluminum potassium sulfate (ALUM) its antibacterial activity is explained with the aqueous extract of alum extraction. The test is carried out by both grams positive and gram negative microorganisms to find out the difference of cleansing range. Through this extraction of alum, they reveal the antimicrobial activity against pathogenic microorganisms. But they didn't mention the daily uses and how it can be used for the real life.

[4] After referring several papers, we were able to find certain interesting details, in that case, there are some mathematical expression to calculate the data of workers and calculate the data of factories in a city. Among them, one of the mathematical method is the regression model, which is used to analyze the data of the workers through certain derivations which makes the works easier for rural area data census.

[5] suggested a similar approach as said in the previous paper that we have mentioned. This paper recommends a mathematical technique to analyze and compare two fire industries using "CHI SQUARE" technique, and it is also used to collect the data of the workers and factories, but it is a difficult expression to use and analyse.

[6] is slightly different from the others because in this they specified the problems of women's working in the fire cracker units, and the survival of the women in the working area can be understood by reading this paper. They have also done the analysis of the hair of the workers by the sedimentation of chemicals and the side effects of those chemicals.

[7] has reviewed about the nature, types, pharmacological, physiochemical, Ayurveda medicines and antimicrobial activity of alum salt. The medicinal values of Alum salt to treat lot of diseases like wounds, ulcer, leprosy, meningitis, disorder of phlegm, bile, vomiting cholera etc. Here we found that the potash alum has the ability to act against the microbes, but the disadvantage of this article is they didn't reveal the technique for treatment

\section{FIELD SURVEY}

We gathered a direct data from the workers to find out the actual problems faced by the employees of firecrackers in their daily life. So, we got permission from one of the fire work industries in Sivakasi. Generally, there the companies classified by the license they have and they are of two categories. One is Chennai license based company which are engaged in the manufacturing of small product of fireworks and other is the Nagpur license based company, which are large industries that concentrate on fancy fireworks manufacturing. We got permission from Chennai license based company, and on analyzing during the manufacture process of the fireworks, the work normally begins at $6 \mathrm{AM}$, which is essentially considered to be the right time for the mixture of chemicals like magnesium sulphate, barium nitrate, Aluminium compounds, potassium perchlorate and copper chloride, and this work ends before $8 \mathrm{AM}$, because the intervention of sunlight during mixture may cause explosions. In the industry, there are separate rooms for every stage of manufacturing process (for example, the room that is allotted for the mixture of chemicals is done in fully covered place with no lights).

Likewise, each manufacturing process will have their separate sections depending on the chemical characteristics. The worker who mixes the chemicals is considered to be the most affected man in the whole factory because his whole body is fully covered by the chemicals, then others are affected due to the direct handling of chemicals without any precautionary actions. They consider the usage of mask or gloves to be uncomfortable to handle the chemicals. This is the reason for which they refuse to wear the gloves. Even in Nagpur license based company, they worker has the same problem. We asked suggestion to them for designing a glove which will be suitable for them to use it daily for their safety. But they refused to use it, and hence we decided to make their cleansing process to be much better. So, we decided to make a soap product which will be beneficial for removing the chemicals and also treats against the pathogenic microorganisms.

\section{A. Problem Statement}

The hidden truth in darkness can be lightened if we torch on it. Likely, we came to know about the actual problem of the workers only after the direct field survey. Workers have cases of chronic headaches, dizziness and ulcers due to high level of exposure towards chemicals during the manufacturing process.

Through our field survey, we have also come to know that they are also affected by eye defects which lead to loss of eye sight in few years, in some rare cases they are affected by nervous disorders, diabetes, etc. Workers refuse to wear masks or gloves while working due to their discomfort, and hence respiratory tract was detected as a possible source of entry of the metal into the

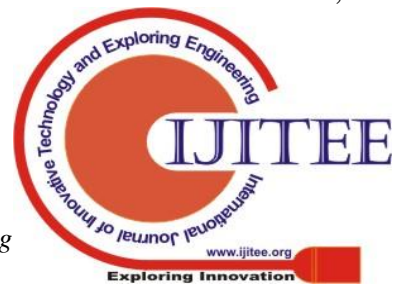


body.

Like said before, every single fire cracker has a specific section that, only few of them are involved in packaging of fire cracks, other than that all are involved in direct handling of chemicals for manufacturing which leads them to major health issues. Here the crucial thing is that they know the danger of the work they are involved in. Even though they are working because the major work business in whole area is fire cracker manufacturing and printing press. So, we can't stop them working, but we can give our best to protect them through cleansing method and giving some awareness about the health issues and about the safety precautions.

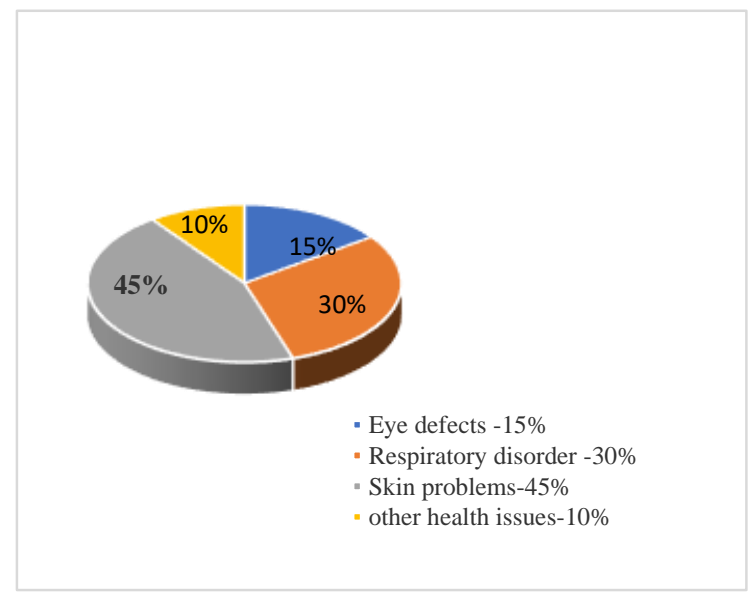

Fig. 1. Survey Analysis

\section{Existing Work}

After the working hours, the employees who would be a daily-waged workers use to clean themselves with a common bar soap which is having a high content of sodium hydroxide (non-domestic soap), and it is generally used for cleaning the cloth and vessels. These type of soaps are more commonly which are commonly used by the workers in fire cracker units due to its low cost and the easy removal of chemicals. Then for cleaning the eye and ear, they use vegetable oil to remove the chemicals.

But the high content of sodium hydroxide leads to major skin diseases, and it is like using a toxic to remove the toxic. Honestly, the workers didn't have the awareness about the soap used, but nearly $95 \%$ of them are using the same soap which causes serious skin disorders in future. So, we tried to make a soap product that will overcome these problems.

\section{PREPARATION OF SOAP (COMPOSITE FORM)}

\section{A. Materials Required}

- Potash Alum - KAl (SO4)2.12H2O.

- Sodium Lauryl sulphate in salt form (SLS) $\mathrm{C} 12 \mathrm{H} 25 \mathrm{NaO} 4 \mathrm{~S}$.

- Ethanol- $\mathrm{CH} 3 \mathrm{CH} 2 \mathrm{OH}$.

- Corn starch [Binder].

\section{B. Materials Description}

\section{Potassium Alum - $\left(\mathrm{AL}\left(\mathrm{SO}_{4}\right)_{2} \cdot 12 \mathrm{H}_{2} \mathrm{O}\right)$}

Any form of Aluminium sulphate is called alum. Usually hydrated double sulphate salt of Aluminium with general formula $\mathrm{XAl}(\mathrm{SO} 4) 2.12 \mathrm{H} 2 \mathrm{O}$ is known as alum, it is a naturally occurring earth material in the form of rocks and sediments that can be converted into a powder or salt like compound. Generally, alum refers to potash alum with the formula $\mathrm{KAl}(\mathrm{SO} 4) 2.12 \mathrm{H} 2 \mathrm{O}$, which we used in the preparation of soap. The nature alum is having a property to treat against pathogenic or microorganism which is soluble in water and sweetish in taste. Above all, it is used in the treatment of skin disorders based on microbes infected skins. That's why we preferred it for the soap preparation.

\section{Sodium Lauryl Sulphate $(\mathrm{SLS})-\left(\mathrm{C}_{12} \mathrm{H}_{25} \mathrm{NaO}_{4} \mathrm{~S}\right)$}

The SLS is already a soap content in the salt state, which is used in the tooth paste and some of the soap industries to produce foam during cleansing. It is also having the property to treat against the microbial organisms. The reason why we prefer the SLS is because, other soap producing salt substance like potassium hydroxide and sodium hydroxide break down the chemical bonds between the alum salt which in turn change its chemical property. So, we can't use other salts except SLS. There will be no breakage of chain during the preparation while using the SLS.

\section{Ethanol- $\left(\mathrm{CH}_{3} \mathrm{CH}_{2} \mathrm{OH}\right)$}

Ethanol is an organic solvent which can be used to dissolve the salts, Ethanol is a volatile, flammable, colorless liquid with a slight characteristic odour. Ethanol is naturally produced by the fermentation of sugars by yeasts or through petrochemical processes. Other solvents like water will not be applicable for this preparation because the SLS is already a soap content which will dissolve it completely and form a foamy layer. So, we can't proceed to further process. That's why we preferred ethanol as solvent. It will partially have dissolved while heating and form as sediment. After that, the ethanol is evaporated out by an exothermic process.

\section{Corn Starch (Binder)}

Corn starch is derived from the corn flour which is produced from the maze or corn. The starch substance is obtained from the endosperm of kernel. It is used as food ingredient in domestic houses. It is easily modified to use in the industries to produce adhesives, like in paper products and textile manufacturing. So, we prefer this to use as a binder which binds the salts and its chemicals strongly to make it as a soap bar content.

\section{a. Preparation}

First take $10 \mathrm{ml}$ of ethanol in a beaker then heat it up to 500c. Then take the salts in the weight ratio of 6:9:15 of (alum: SLS: binder) then after few minutes of heating, dissolve the SLS in the ethanol steadily, and then continue by dissolving the alum at certain period, which will partially dissolve the salts. Then cool it down to room temperature by setting it in the form of soap shape.

Within few minutes, we will get a colloidal state of the substance, and at that time, mix the corn starch well using stir rod which in turn holds the chemical bonds stronger and make it as a bar soap. After this set up, leave it for 12 hours, and in the meantime, the ethanol and water content will evaporate in the air. We then get an antibacterial soap which can be used to remove the 
chemicals.

\section{b. Methodology}

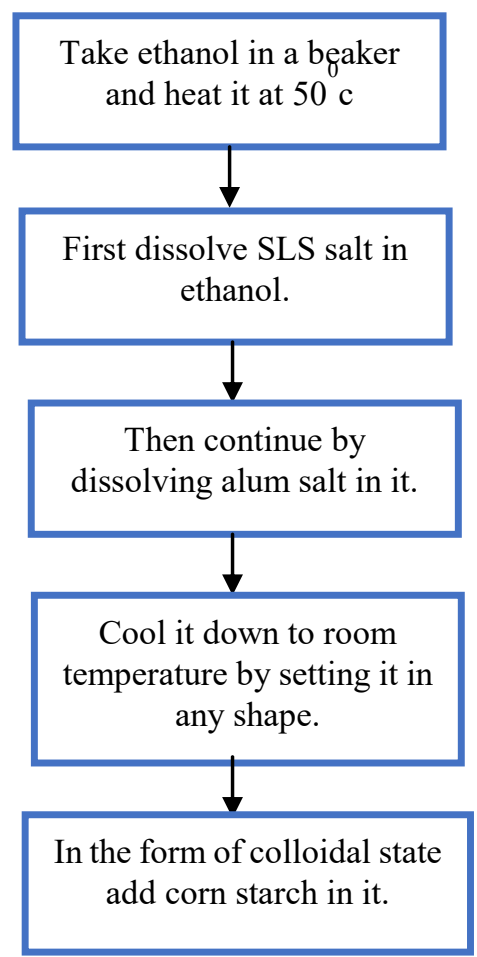

Fig. 2. Block Diagram

\section{c. Chemical Reaction}

While we dissolve the salts in the ethanol, the organic solvent leads to the binding actions in it. The Sodium lauryl sulphate SO4- ions move towards outside then the $\mathrm{Na}+$ ions are placed outside the molecular chains. Likewise, after dissolving the alum salt, the ions will be reversed, then the $\mathrm{K}+$ ions are attracted to the inner side of the molecular chain and holds on it, and then a foamy layer produced from aluminum and sulphate are held together in the outside of the molecule chain. These are the actions that takes place while dissolving the salts, the reversal of ions attracts to each other which forms an antibacterial soap.

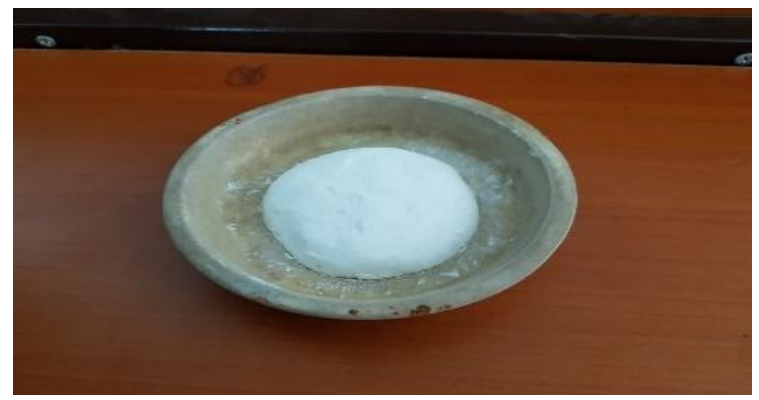

Fig. 3. Block Diagram

When the reaction takes place by ethanol the, some of the sodium ions are replaced by the positive part of the alum. So, the harmful sodium ions are suppressed by the potassium, it is nothing but simple ionic change. Hence the soap what we have manufactured tends to be a "COMPOSITE PRODUCT" with complex phenomena and aids the labours indulged in harmful preparation and mixtures of pyrotechnical chemicals, and in the stuffing the same into crackers shell.

\section{d. Assessment of Antimicrobial Activity}

The soap sample was assessed for its antibacterial activity against Gram positive organism (Bacillus cereus) and Gram negative organism (Escherichia coli) by direct placement in Mueller-Hinton agar plates and well-diffusion method. For direct placement, a small piece of soap was placed on the Mueller-Hinton agar plate spread with the organism.

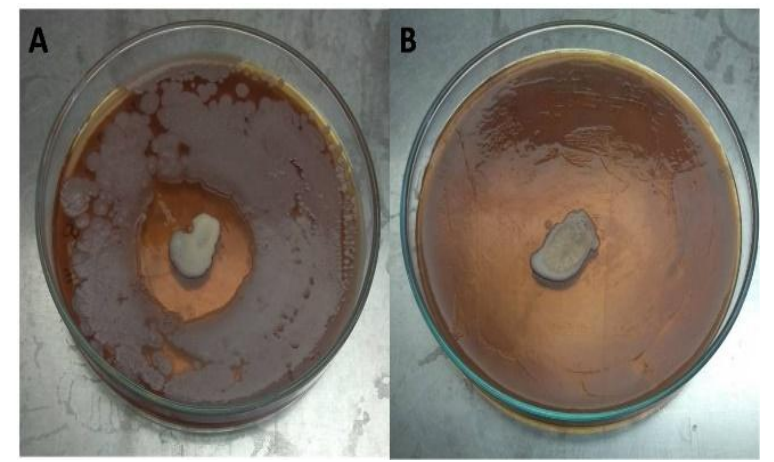

Fig. 4. Direct placement Method, A. Bacillus cereus B. Escherichia coli

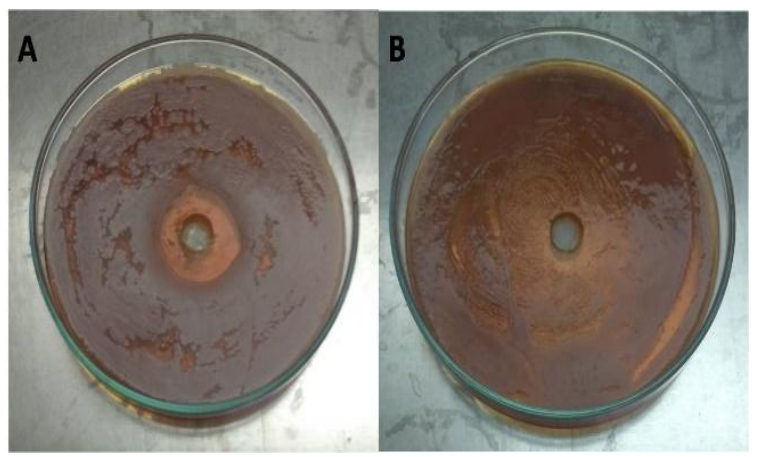

Fig. 5. Well diffusion Method, A. Bacillus cereus B. Escherichia coli

For well diffusion method, soap was dissolved in sterile distilled water and then loaded in the wells in Mueller-Hinton agar plate inoculated with organisms. The soap showed antibacterial activity against Bacillus cereus but not against Escherichia coli. The diameter of the zone of inhibition in Bacillus cereus was measured to be $24 \mathrm{~mm}$ by direct placement, whereas, it was $32 \mathrm{~mm}$ in well diffusion method.

\section{RESULT AND DISCUSSION}

Based on the antimicrobial analysis report, we can fulfil the needs of the workers with our manufacturing soap material. Through the field survey and adopting certain ethical procedurals, we made the need analysis for this and we have exhibited a plan for the necessary materials that is required to manufacture the soap product, which we have designed in a way to be more compatible (user-friendly), economic and ample longevity, more readily to diminish the rate of susceptibility for the workers who are employed and operate in the packing of fire-powders and subsequent materials into the crackers with their bare hands, irrespective of their gender. 


\section{CONCLUSION}

Workers face various risks in using the existing product of soap, hence regarding as the path-way that leads to major health issues. We have designed a product which will overcome these problems. Our soap product not only clears the chemical from the hand, but also treats the affected skin with its antimicrobial activity. The soap will provide ample protection and be more comfortable for the employees of firework industries and has the ability to restrain the harm caused by dust particles and chemicals.

\section{REFERENCES}

1. Dhruv katoria, Dhruv Mehta, Dhruv Sehgal \& Sameer Khan, "A Review of risk to workers associated with fire work industry" (Research India publication: 2013).

2. N.Rajathilagam, "Analysis of safety in Fireworks Industries by $\mathrm{CHI}$ SQUARE analysis-Virudhunagar District", (International journal of management and social science Research: February 2016).

3. Ilham Abass Bnyan PhD, Abdulsamie Hassan Alta'ee PhD, Nadia Hassan Kadhum MSc, "Antibacterial Activity of Aluminium Potassium Sulfate and Syzygium Aromaticum Extract Against Pathogenic Microorganisms", Journal of Natural Sciences Research (2017).

4. Dr.R.Sophia Porchelvi, P.Jamuna Devi, "Regression model for people working in Fire work Industry-Virudhunagar District", (International journals of scientific and Research publication: April 2015). Regression model for people working in Fire work Industry-Virudhunagar District.

5. Dr.R.Gandhinathan, A.Ravi, "Analysis of safety climate in fireworks Industries in Tamilnadu." (International journal of scientific and Research publication: December 2013)

6. R.C.Saravana Kumar, Dr.G.Karunanidhi, "A study on problems pertaining of women labors in fireworks Industry with special reference to Sivakasi”, (International journal of management and social science Research: March 2016).

7. Akhtar Ali, Hamiduddin, Mohammad Zaigham, "Shibb-e-yaman (alum) a unique drug and its utilization in unani medicine: a physicochemical and pharmacological review" (Journal of Natural Sciences Research: March 2017)

\section{AUTHORS PROFILE}

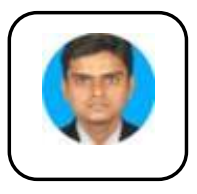

Dr. G. Vishnuvarthanan, born in 1986 , has research stints in the avenues of medical image processing and artificial intelligence. He was awarded $\mathrm{PhD}$ in the year 2015 and bachelor's degree in Instrumentation and Control Engineering by 2007, and Master's Degree in VLSI by 2009. He has more than ten years of teaching and research experience and has his affiliation as Associate Professor with the Department of Biomedical Engineering of School of Bio and Chemical Sciences in the Kalasalingam Academy of Research and Education, Tamilnadu, India.

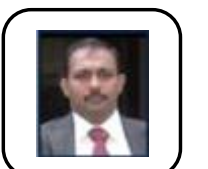

Pallikonda Rajasekaran Murugan, Born in Srivilliputhur, Virudhunagar District of Tamil Nadu in 1980, he had his schooling in the same town and graduated in Electronics and Instrumentation Engineering in 2001 from Shanmugha College of Engineering, Thanjavur and completed his M. Tech. degree in 2002 with second Rank in SASTRA University. He pursued his doctoral program in Anna University, Chennai. Starting as a Lecturer in 2003, he became Asst. Professor in 2008, Associate Professor in 2009 and Professor in 2012 in Kalasalingam Academy of Research and Education. He had a deep involvement in Bio-signal Processing research. His work on the Image Segmentation for identification of brain tumor and image reconstruction and compression using medical images for diagnosis. Over $150 \mathrm{~B}$. Tech students, $75 \mathrm{M}$. Tech students, and 8 Doctorates stand testimony for his productivity in Image Processing, Wireless Sensor Networks, and Biomedical Instrumentation research. He has so far published more than 50 papers in national and international journals and conferences. He is a Fellow of Indian Society for Technical Education (ISTE), Institute of Electrical and Electronics Engineers (IEEE), Asia-Pacific Chemical, Biological \& Environmental Engineering Society (APCBEES), Institution of Engineers (India) (IE),
International Association of Engineers (IAENG) and International Association of Computer Science and Information Technology (IACSIT).

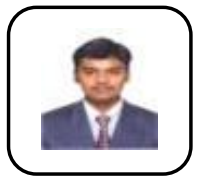

Sakthivel Sankaran received B-Eng. in Electronics and Communication Engineering, May 2013 and M. Tech in (Biomedical Engineering) at VIT University, Vellore, May 2015. Currently working as an Assistant Professor in Biomedical Engineering department at Kalasalingam Academy of Research and Education, Krishnankoil. His research interests are Biomechanics, Rehabilitation Engineering and Biomedical Instrumentation. He has so far published more than 09 papers in national and international journals and conferences. He is a Fellow of Indian Society for Technical Education (ISTE), Institute of Electrical and Electronics Engineers (IEEE), Biomedical Engineering Society of India (BMESI) (sakthivelsankaran92@gmail.com).

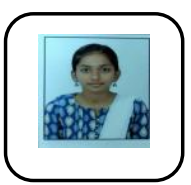

Sathiyaa Sri Suthanthiram pursuing her B. Tech Biomedical Engineering at Kalasalingam Academy of Research and Education, Krishnankoil..

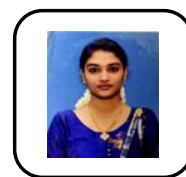

Jothi Malar Thirumurugan, pursuing her B.Tech Biomedical Engineering at Kalasalingam Academy of Research and Education, Krishnankoil.

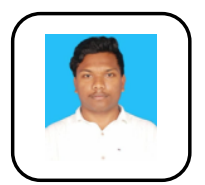

Mohamed Sheik Mydeen Ismail pursuing his B Tech Biomedical Engineering at Kalasalingam Academy of Research and Education, Krishnankoil.

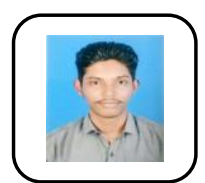

Arjunan Senthilkumar pursuing his B. Tech Biomedical Engineering at Kalasalingam Academy of Research and Education, Krishnankoil. 